\title{
Outcomes of surgery for giant hepatic hemangioma
}

\author{
Qing-song Xie, Zi-xiang Chen, Yi-jun Zhao, Heng Gu, Xiao-ping Geng and Fu-bao Liu*
}

\begin{abstract}
Background: The surgical indications for liver hemangioma remain unclear.

Methods: Data from 152 patients with hepatic hemangioma who underwent hepatectomy between 2004 and 2019 were retrospectively reviewed. We analyzed characteristics including tumor size, surgical parameters, and variables associated with Kasabach-Merritt syndrome and compared the outcomes of laparoscopic and open hepatectomy. Here, we describe surgical techniques for giant hepatic hemangioma and report on two meaningful cases.

Results: Most (63.8\%) patients with hepatic hemangioma were asymptomatic. Most (86.4\%) tumors from patients with Kasabach-Merritt syndrome were larger than $15 \mathrm{~cm}$. Enucleation (30.9\%), sectionectomy (28.9\%), hemihepatectomy (25.7\%), and the removal of more than half of the liver (14.5\%) were performed through open (87.5\%) and laparoscopic (12.5\%) approaches. Laparoscopic hepatectomy is associated with an operative time, estimated blood loss, and major morbidity and mortality rate similar to those of open hepatectomy, but a shorter length of stay. 3D image reconstruction is an alternative for diagnosis and surgical planning for partial hepatectomy.
\end{abstract}

Conclusion: The main indication for surgery is giant $(>10 \mathrm{~cm}$ ) liver hemangioma, with or without symptoms. Laparoscopic hepatectomy was an effective option for hepatic hemangioma treatment. For extremely giant hemangiomas, 3D image reconstruction was indispensable. Hepatectomy should be performed by experienced hepatic surgeons.

Keywords: Hepatic hemangioma, Giant, Surgical management, Surgical indication, Surgical technique, 3D image reconstruction

\section{Introduction}

Cavernous hemangioma, which is usually solitary and asymptomatic, is the most common benign tumor of the liver, with a reported prevalence of $3-20 \%$ based on autopsy series [1]. Hepatic hemangioma frequently presents in the fourth and fifth decades of life, and the female:male incidence ratio is 6:1. Giant hepatic hemangioma, which is defined as a tumor larger than $10 \mathrm{~cm}$ in diameter, is uncommon and rarely causes symptoms [2]. Giant hepatic hemangioma is present in less than $10 \%$ of cases [3].

\footnotetext{
*Correspondence: fubaoliu0551@sina.com

Hepatopancreatobiliary Surgery, Department of general surgery, The First Affiliated Hospital of Anhui Medical University, 120\# Wanshui Road, Hefei 230022, Anhui, China
}

Treatments for hepatic hemangioma include radiofrequency ablation (RFA), monoclonal antibody therapy, radiation therapy (RT), trans-arterial embolization (TAE), interferon therapy, liver transplantation, and surgical procedures (enucleation and resection). The therapeutic mechanism of RFA may be its induction of localized thermal injury on the flat endothelial cells constituting the walls of widely dilated non-anastomotic vascular spaces [4-6]. The advantages of RFA for the treatment of hepatic hemangioma include the lack of requirement for a safety margin and the ability to achieve clear shrinkage of the tumor around the ablation zone [7]. The main disadvantage of RFA for hepatic hemangioma is the risk of hemolysis, including hemoglobinuria, hemolytic jaundice, anemia, and even renal damage, esophageal perforation, and thrombosis. 
The risks of these adverse outcomes increase with tumor size $[6,8,9]$. The mechanism for the efficacy of RT may be its destruction of vascular endothelial cells and smooth muscle cells, resulting in vascular thrombosis, necrosis, and fibrosis $[4,10,11]$. However, because of treatment-related liver toxicity and the longterm potential for secondary malignancies, RT is rarely recommended as a first-line therapy for liver hemangioma [11]. TAE causes arterial blood supply blockage and subsequent shrinkage of tumors, with the potential complications of ischemia, intracavitary bleeding, and infection [12]. TAE is recommended to reduce hemangioma size, especially when the tumor is larger than $20 \mathrm{~cm}$ in diameter [13-16], and is used in cases of preoperative hepatic hemangioma rupture [17]. Liver transplantation due to giant hepatic hemangioma has been reported in patients with Kasabach-Merritt syndrome [18-22]; however, further research in this area is needed. Hepatic resection has been used to treat hepatic hemangioma since 1898 [23]. Approximately one century later, enucleation was first used for the treatment of hepatic hemangioma, with the reported advantages of safety, minimal blood loss, lower complication rates, and maximum preservation of the normal liver parenchyma [24-27]. However, as hepatic hemangiomas grow slowly and rarely rupture [28], surgical treatment is not always necessary. In addition, a study of 5542 cases of liver resection performed in the United States between 2005 and 2011 showed that the mortality rates at 30 postoperative days were $0.9 \%$ for 1164 cases with benign liver tumors and $1.4 \%$ for 4378 cases with metastatic liver cancer. The mortality rates were associated with age and surgical complications, but not with the nature of the lesions or the range of liver resection [29]. Thus, surgical treatment should be used with care for benign liver lesions. The present study was a retrospective analysis of surgical outcomes in patients with giant hepatic hemangiomas.

\section{Methods \\ Patient selection}

Between 2004 and 2019, 152 patients with the primary diagnosis of hepatic hemangioma were referred for surgical evaluation at the First Affiliated Hospital of Anhui Medical University. Hepatic hemangioma was diagnosed based on imaging studies, clinical data, and histological analyses. The indication for operation was giant $(>10 \mathrm{~cm})$ liver hemangioma, with or without symptoms and Kasabach-Merritt syndrome (characterizing with thrombocytopenia and disseminated intravascular coagulation, and occasional fatal hemorrhage).
Patients' medical records were reviewed retrospectively and we report two notable cases.

\section{Statistical analysis}

Results are presented as means \pm standard errors of the mean. Analysis of variance, Student's $t$ test, and the $X^{2}$ test were used to determine the significance of differences between experimental groups. All statistical analyses were performed using SPSS software (ver. 19.0 for Windows; SPSS Inc., Chicago, IL, USA). $P$ values $<0.05$ were taken to indicate statistical significance.

\section{Results}

The mean age of patients was 51.6 (range, 26-71) years, and most $(61.8 \%)$ patients were female. Most (63.8\%) patients with hepatic hemangioma were asymptomatic, and $29.6 \%$ of patients had hepatic hemangiomas larger than $15 \mathrm{~cm}$ (Table 1). Among 22 patients with Kasabach-Merritt syndrome, $86.4 \%$ of hepatic hemangiomas were larger than $15 \mathrm{~cm}$. Most (54.5\%) patients with Kasabach-Merritt syndrome had abdominal pain. The number of platelets in patients (range, $56 \times 10^{9} / 1-89 \times 10^{9} / \mathrm{l}$ ) increased after surgery (range, $75 \times 10^{9} / \mathrm{l}-143 \times 10^{9} / \mathrm{l}$ ) (Table 2).

Most (64.5\%) hemangiomas were solitary. Hepatic hemangiomas were treated by enucleation (30.9\%), sectionectomy $(28.9 \%)$, hemihepatectomy $(25.7 \%)$, and the removal of more than half of the liver (14.5\%) through open (87.5\%) and laparoscopic (12.5\%) approaches (Table 3). Compared with open hepatectomy, laparoscopic hepatectomy was associated with a similar operative time, estimated blood loss, and major morbidity and mortality, but a shorter length of stay $(P<0.01)$ (Table 4$)$.

Table 1 Background characteristics of patients undergoing hepatectomy for hemangioma

\begin{tabular}{ll}
\hline Basic data & $\mathrm{N}$ \\
\hline Number of cases & 152 \\
Age (years) & \\
Mean \pm SD & $51.6 \pm 9.6$ \\
Range & $26-71$ \\
Gender & \\
Male (\%) & $58(38.2)$ \\
Female (\%) & $94(61.8)$ \\
Symptoms & \\
No symptoms (\%) & $97(63.8)$ \\
Abdominal pain (\%) & $55(36.2)$ \\
Tumor size & $107(70.4)$ \\
$>10 \mathrm{~cm}$ and $<15 \mathrm{~cm}(\%)$ & $48(29.6)$ \\
$>15 \mathrm{~cm}(\%)$ &
\end{tabular}


Table 2 Background characteristics of patients with KasabachMerritt syndrome undergoing hepatectomy for hemangioma

\begin{tabular}{ll}
\hline Basic data & $\mathrm{N}$ \\
\hline Number of cases & 22 \\
Age (years) & \\
Mean \pm SD & $56.4 \pm 10.6$ \\
Range & $36-71$ \\
Gender & \\
Male (\%) & $7(31.8)$ \\
Female (\%) & $15(68.2)$ \\
Symptoms & \\
No symptoms (\%) & $10(45.5)$ \\
Abdominal pain (\%) & $12(54.5)$ \\
Platelet count $\left(\times 10^{9} /\right.$ l) & \\
Pre-operation (range) & $56-89$ \\
Post-operation (range) & $75-143$ \\
Tumor size & \\
$>10 \mathrm{~cm}$ and $<15 \mathrm{~cm}(\%)$ & $3(13.6)$ \\
$>15 \mathrm{~cm}(\%)$ & $19(86.4)$ \\
\hline
\end{tabular}

Table 3 Surgical parameters of patients who underwent hepatectomy for hemangioma

\begin{tabular}{ll}
\hline Variables & Data \\
\hline Tumor number & \\
Solitary (\%) & $98(64.5)$ \\
Multiple (\%) & $54(35.5)$ \\
Tumor size (cm) & \\
Mean \pm SD & $12.9 \pm 3.3$ \\
Range & $10-23$ \\
Hepatectomy procedure & \\
Enucleation (\%) & $47(30.9)$ \\
Sectionectomy (\%) & $44(28.9)$ \\
Hemihepatectomy (\%) & $39(25.7)$ \\
More than hemihepatectomy (\%) & $22(14.5)$ \\
Operational approach & \\
Open approach & $133(87.5)$ \\
Laparoscopic approach & $19(12.5)$ \\
Operative time (min) (range) & $177(60-300)$ \\
Estimated blood loss (ml) (range) & $343(10-1200)$ \\
Major morbidity or mortality & 0 \\
\hline
\end{tabular}

For patients with complex and especially large hepatic hemangiomas, three-dimensional (3D) image reconstruction was performed to understand future remnant liver volumes and the relationships between intrahepatic blood vessels and tumors (Fig. 1).

One notable case was that a 62-year-old female patient with a giant hemangioma in the right lobe of the liver was misdiagnosed with hepatocellular carcinoma. In 2006, the patient's physical examination revealed a liver mass. The patient was diagnosed with hepatocellular carcinoma and underwent five rounds of transhepatic arterial chemotherapy and embolization and multiple cytokineinduced killer cell treatments at another hospital. In December 2015, the patient was admitted to our hospital and we determined that she was not infected with hepatitis B virus and was alpha-fetoprotein negative. Computed tomography $(\mathrm{CT})$ revealed a large mass in the right lobe of the liver, and the patient's liver reserve function was normal. Thus, she underwent extensive right hepatectomy, and the final pathologically confirmed diagnosis was hepatic hemangioma (Table 5; Fig. 2).

Another significant case occurred in a 45-year-old male patient (a seaman) with symptoms of obstructive jaundice who had a $\sim 5-\mathrm{cm}$ hepatic hemangioma near the first porta hepatis. $\mathrm{CT}$ and magnetic resonance imaging (MRI) revealed that the hepatic hemangioma was located at the first porta hepatis and compressed the intrahepatic bile duct, resulting in obstructive jaundice. We enucleated the tumor and the patient's bilirubin level returned to normal (Table 6; Fig. 3).

For extremely giant hemangiomas, the surgical procedure was as follows. First, 3D image reconstruction was performed and radiographic results were studied scrupulously to design an optimal operative protocol. Next, a transverse incision was made in the epigastrium corresponding to the longest diameter of the tumor to fully expose the tumor and first porta hepatis. For obese patients or especially giant tumors, incisions extended to the xiphoid process. The first porta hepatis was exposed and the hepatic portal blocking band was prearranged; then, the hepatic artery and portal vein on the tumor side were ligatured and severed to shrink the tumor. The second porta hepatis was exposed and dissected. The tumor was bandaged to reduce bleeding, and liver resection was performed using hectogram pliers along the border between the liver and tumor. The intrahepatic small vessels and bile ducts were disposed of using titanium clips. Autologous blood transfusion was performed, and the middle hepatic vein was carefully protected as much as possible. Finally, the hepatic cutting surface was sutured with 4-0 prolene for hemostasis, and drainage tubes were placed under the liver and on the liver section (Fig. 4).

\section{Discussion}

Hepatic hemangioma is the most common benign liver tumor [30-32]. Some hemangiomas contain estrogen receptors and grow during pregnancy, oral contraceptive use, or Rogaine ${ }^{\circledR}$ and/or steroid administration [4, 33, 34]. Thus, female sex hormones play an important role in the development of hepatic hemangioma, and these tumors are more common in women. Nearly two-thirds 
Table 4 Surgical parameters of patients who underwent hepatectomy for hemangioma

\begin{tabular}{|c|c|c|c|}
\hline Variables & Open approach & Laparoscopic approach & $P$ \\
\hline N (\%) & $133(87.5)$ & $19(12.5)$ & \\
\hline Age $($ mean $\pm S D)$ & $52.8 \pm 9.4$ & $50.8 \pm 11.9$ & 0.400 \\
\hline \multicolumn{4}{|l|}{ Gender } \\
\hline Male & $50(37.6)$ & $11(57.9)$ & 0.091 \\
\hline Female & $83(62.4)$ & $8(42.1)$ & \\
\hline Tumor size (cm) (mean \pm SD) & $13.0 \pm 3.4$ & $12.0 \pm 2.6$ & 0.152 \\
\hline Operative time (min) (mean \pm SD) & $167.4+57$ & $177.6 \pm 59.4$ & 0.488 \\
\hline Estimated blood loss (ml) (mean \pm SD) & $319 \pm 245$ & $282 \pm 190$ & 0.537 \\
\hline Major morbidity or mortality & 0 & 0 & \\
\hline LOS (mean \pm SD) & $8 \pm 0.8$ & $5 \pm 0.6$ & $<0.01^{*}$ \\
\hline
\end{tabular}

LOS Length of stay

*Significant difference

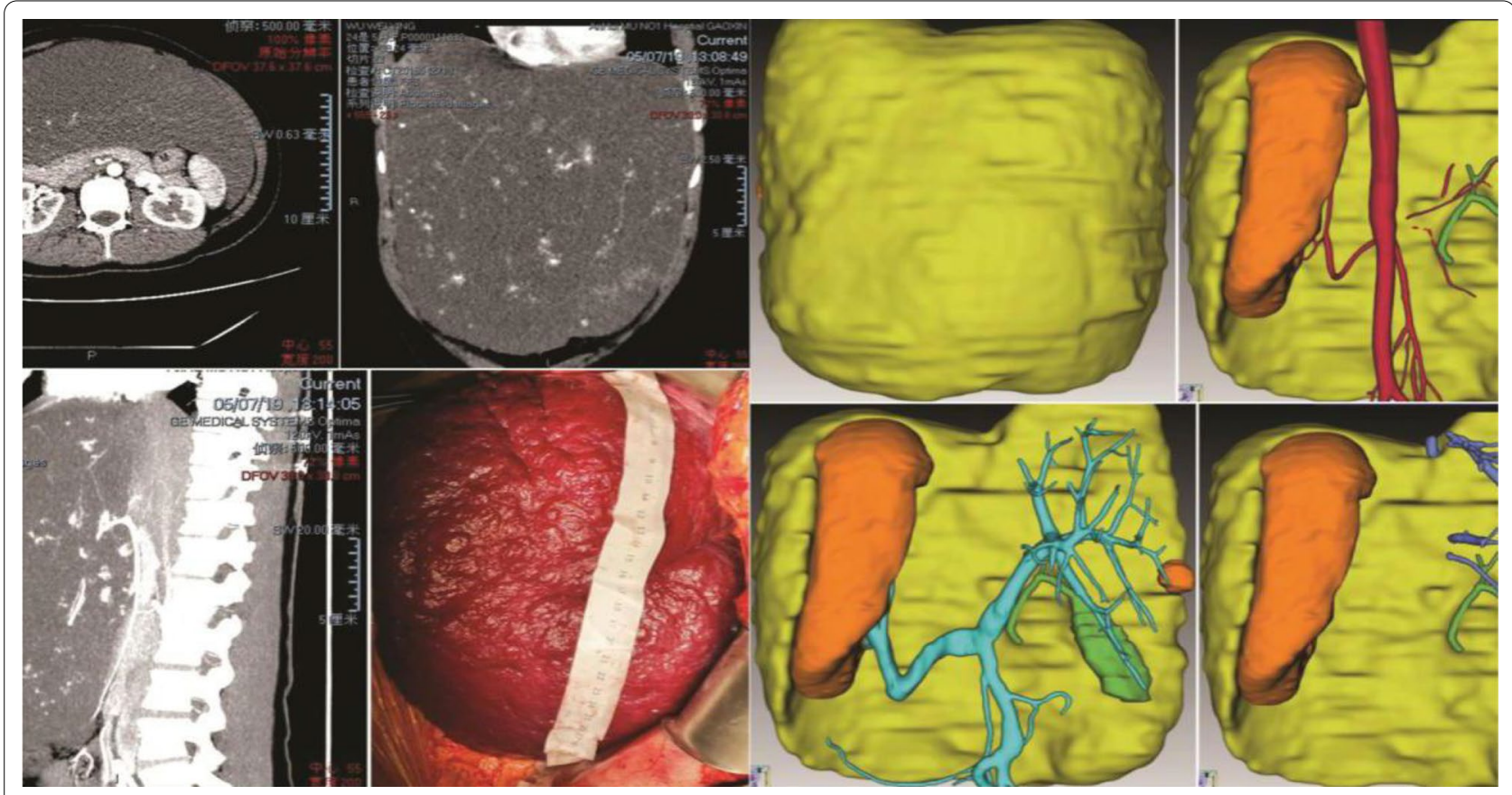

Fig. 1 A 24-year-old woman with two children was diagnosed with an extremely giant hepatic hemangioma in the left lobe of her liver after reporting abdominal pain. The tumor, extending below the belly button, had a maximum diameter of $38 \mathrm{~cm}$. The 3D-reconstructed image shows the tumor (yellow), normal liver (orange), and the relationships between the tumor and hepatic vessels. The patient also had Kasabach-Merritt syndrome. The number of platelets increased from $57 \times 10^{9} / \mathrm{I}$ to $100.5 \times 10^{9} / \mathrm{I}$ after surgery

(61.8\%) of patients with hepatic hemangioma in our sample were female, consistent with previously reported findings $[4,34]$.

As the treatment strategy for hepatic hemangioma depends on tumor size, the definition of giant hepatic hemangioma is crucial. Different criteria for this definition have been reported. The majority of authors use the criterion of diameter $>4 \mathrm{~cm}[2,35]$, whereas others use diameter $>5 \mathrm{~cm}$ [36] and a minority of authors use diameter $>10 \mathrm{~cm}$ [37]. We believe that the definition of giant hemangioma should be based on diameter $\geq 10 \mathrm{~cm}$, as $10-\mathrm{cm}$ hemangiomas can cause more serious symptoms than can 4-cm tumors. Thus, we focused on patients with hepatic hemangiomas larger than $10 \mathrm{~cm}$ in this study.

The case of the female patient with a hepatic hemangioma misdiagnosed as hepatocellular carcinoma clarifies the importance of the accurate diagnosis of hepatic 
Table 5 One case of giant hemangioma in the right lobe of the liver misdiagnosed as hepatocellular carcinoma

\begin{tabular}{ll}
\hline Variables & Data \\
\hline Age & 62 years old \\
Gender & Female \\
BMI & $27.48 \mathrm{~kg} / \mathrm{m}$ \\
Symptoms & Abdominal pain \\
Laboratory data & HBV $(-)$, AFP( - ), ICG15 min (2.8\%), Child-Pugh (A) \\
Tumor location and size & Right lobe of liver, D = 17 cm and weighted about 1500 g \\
Past medical history & 5 rounds of TACE, multiple CIK treatments \\
Hepatectomy procedure & Extensive right hepatectomy \\
Operation and portal occlusion time & 120 and 20 min \\
Estimated blood loss & 170 ml \\
Pathological findings & Hepatic hemangioma \\
\hline
\end{tabular}

HBV Hepatitis b virus, AFP alpha fetoprotein, ICG 15-min indocyanine green clearance, TACE Transhepatic arterial chemotherapy and embolization, CIK Cytokineinduced killer cell

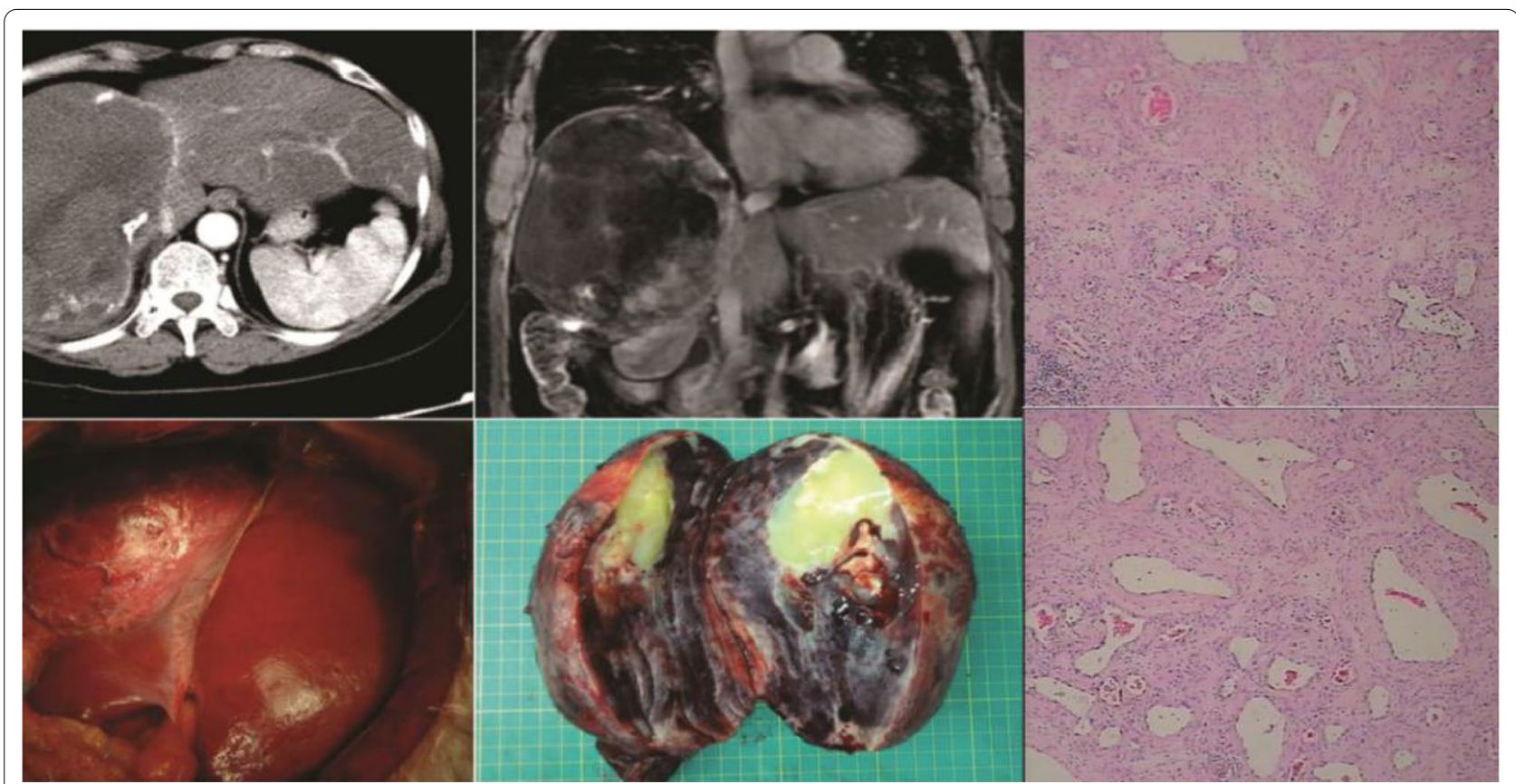

Fig. 2 A 62-year-old female patient with a giant hemangioma in the right lobe of the liver was misdiagnosed with hepatocellular carcinoma. In 2006, the patient underwent physical examination, which revealed a liver mass. The patient was diagnosed with hepatocellular carcinoma and underwent five rounds of transhepatic arterial chemotherapy and embolization and multiple cytokine-induced killer cell treatments at another hospital. In December 2015, the patient was admitted to our hospital and we determined that she was not infected with hepatitis b virus and was a-fetoprotein negative. The CT image shows a large mass in the right lobe of the liver. The patient's liver reserve function was normal. She underwent extensive right hepatectomy and was given a final pathological diagnosis of hepatic hemangioma

hemangioma. The diagnostic methods for hepatic hemangioma include ultrasonography, CT, MRI, scintigraphy and positron-emission tomography combined with CT, angiography, and biopsy. The central non-enhancing components, central hemorrhagic changes, and intralesional arterio-portal or arterio-venous shunts of giant $(>10 \mathrm{~cm})$ hemangiomas may lead to misdiagnosis
[37-39]. Thus, the differentiation of hemangioma from liver metastasis in patients with primary liver neoplasms and from hepatocellular carcinoma in patients with cirrhosis is important. 3D visualization is an alternative for diagnosis and surgical planning for partial hepatectomy [40-43]. In our sample, we evaluated hepatic hemangiomas routinely using B-mode ultrasonography, MRI, CT, 
Table 6 One case of giant hepatic hemangioma near the first porta hepatis

\begin{tabular}{ll}
\hline Variables & Data \\
\hline Age & 45 years old \\
Gender & Male \\
BMI & $22.2 \mathrm{~kg} / \mathrm{m}^{2}$ \\
Symptom & Obstructive jaundice \\
Total bilirubin (TBIL) & Pre/post-operation: \\
& $123.5 / 18.7 \mu \mathrm{mol} / \mathrm{l}$ \\
Direct bilirubin (DBIL) & Pre/post-operation: \\
& $100.8 / 10.3 \mu \mathrm{mol} / \mathrm{l}$ \\
Indirect bilirubin (IBIL) & Pre/post-operation: $22.7 / 8.4 \mu \mathrm{mol} / \mathrm{l}$ \\
Laboratory data & HBV $(-)$, AFP(-) \\
Tumor location and size & Near the first porta hepatis and \\
& $5.8 \mathrm{~cm}$ \\
Past medical history & None \\
Hepatectomy procedure & Enucleation \\
Operation and portal occlusion & 65 and 0 min \\
time & $100 \mathrm{ml}$ \\
Estimated blood loss &
\end{tabular}

HBV Hepatitis b virus, AFP alpha fetoprotein

and serum tumor markers. Imaging consultation was adopted for intractable cases. We also used 3D reconstruction for further diagnosis and surgical planning in cases of complex and giant hepatic hemangiomas.

Hepatic hemangiomas tend to grow slowly and rupture infrequently $[28,44]$. As patients with hepatic hemangioma can be considered to be 'normal', surgical indications and techniques must be strictly controlled. Japanese surgeons have deemed that surgical resection may be justified for tumors less than $5 \mathrm{~cm}$ in diameter when malignancy is suspected; that patients with abdominal symptoms or coagulopathy are candidates for surgery when the tumor diameter exceeds $10 \mathrm{~cm}$; that hepatectomy should be performed by experienced hepatic surgeons for tumors larger than $15 \mathrm{~cm}$; and that asymptomatic hepatic hemangiomas $(5-10 \mathrm{~cm})$ require no surgical intervention [45]. In the current study, most tumors were larger than $10 \mathrm{~cm}$, of which $29.6 \%$ were larger than $15 \mathrm{~cm}$. About one-third (36.2\%) of patients had symptoms, and 22 patients had Kasabach-Merritt syndrome. The sample included an exceptional case of a hemangioma less than $10 \mathrm{~cm}$ in diameter located at the first porta hepatis. As this small tumor resulted in obstructive jaundice and the patient was a seaman, we enucleated it.

Hepatic resection has historically been the most common therapy for hepatic hemangioma [23]. However, enucleation is now used more frequently and is favored by surgeons due to its safety and the reduction of blood loss and complication rates [24, 25, 27, 46]. The location of a tumor determines the surgical plan. Hepatectomy should be performed when the hepatic hemangioma is located deep within the liver parenchyma, does not present a surface free from the Glisson capsule, or occupies the entire lobe [47]. In the present study, the majority (69.1\%) of patients underwent hepatectomy, and 14.5\% of patients underwent extended hemihepatic resection. Only $30.9 \%$ of patients underwent enucleation, as nearly all tumors were more than $10 \mathrm{~cm}$ in diameter; $29.6 \%$ of tumors were greater than $15 \mathrm{~cm}$ in diameter, frequently occupying more than half of the liver.

Laparoscopic liver resection is used widely for hepatic hemangioma because it decreases postoperative complications, enables more rapid patient discharge, and supports better postoperative cosmetic satisfaction [4852]. Laparoscopic resection of even an extremely giant $(>20 \mathrm{~cm}$ ) hepatic hemangioma has been reported [53]. However, the results of randomized clinical trials comparing laparoscopic to open liver resection are not yet available, and the learning curve for laparoscopic resection and scoring systems for the degree of its difficulty will continue to evolve [54]. The results of a recent nonrandomized controlled trial suggest that a laparoscopic approach to hepatic hemangioma treatment improves short-term surgical outcomes [55]. Our data revealed no difference in the operative time, estimated blood loss, and major morbidity and mortality between laparoscopic and open liver resection for hepatic hemangioma, with a significant reduction in the length of stay associated with laparoscopic liver resection. Although our study was retrospective, we recommend laparoscopic hepatectomy as a treatment option for hepatic hemangioma.

Kasabach-Merritt syndrome is characterized by the occurrence of disseminated intravascular coagulation due to hepatic hemangioma, and has a fatality rate of $7-10 \%$ that rises to $80 \%$ in the first year [56]. Hepatectomy [56], liver transplantation $[18,22]$, and steroid or beta-blocker therapy [57] have been reported to effectively treat Kasabach-Merritt syndrome in patients with hepatic hemangioma. Many patients with Kasabach-Merritt syndrome in our sample had extremely giant $(>15 \mathrm{~cm})$ tumors, which made surgery more difficult.

We summarize our center's surgical recommendations for giant hepatic hemangioma as follows. A large curved incision should be created in the upper abdomen to expose the tumor body and the first porta. The first hilum of the liver should be exposed as much as possible, the hepatic artery/portal vein of the affected side should be ligated and devascularized to shrink the tumor, and the liver parenchyma should be transected as far as possible within 30 min after blocking while avoiding repeated opening to minimize blood loss. Hemihepatic blood flow occlusion, hepatic inflow occlusion, and complete hepatic vascular occlusion 

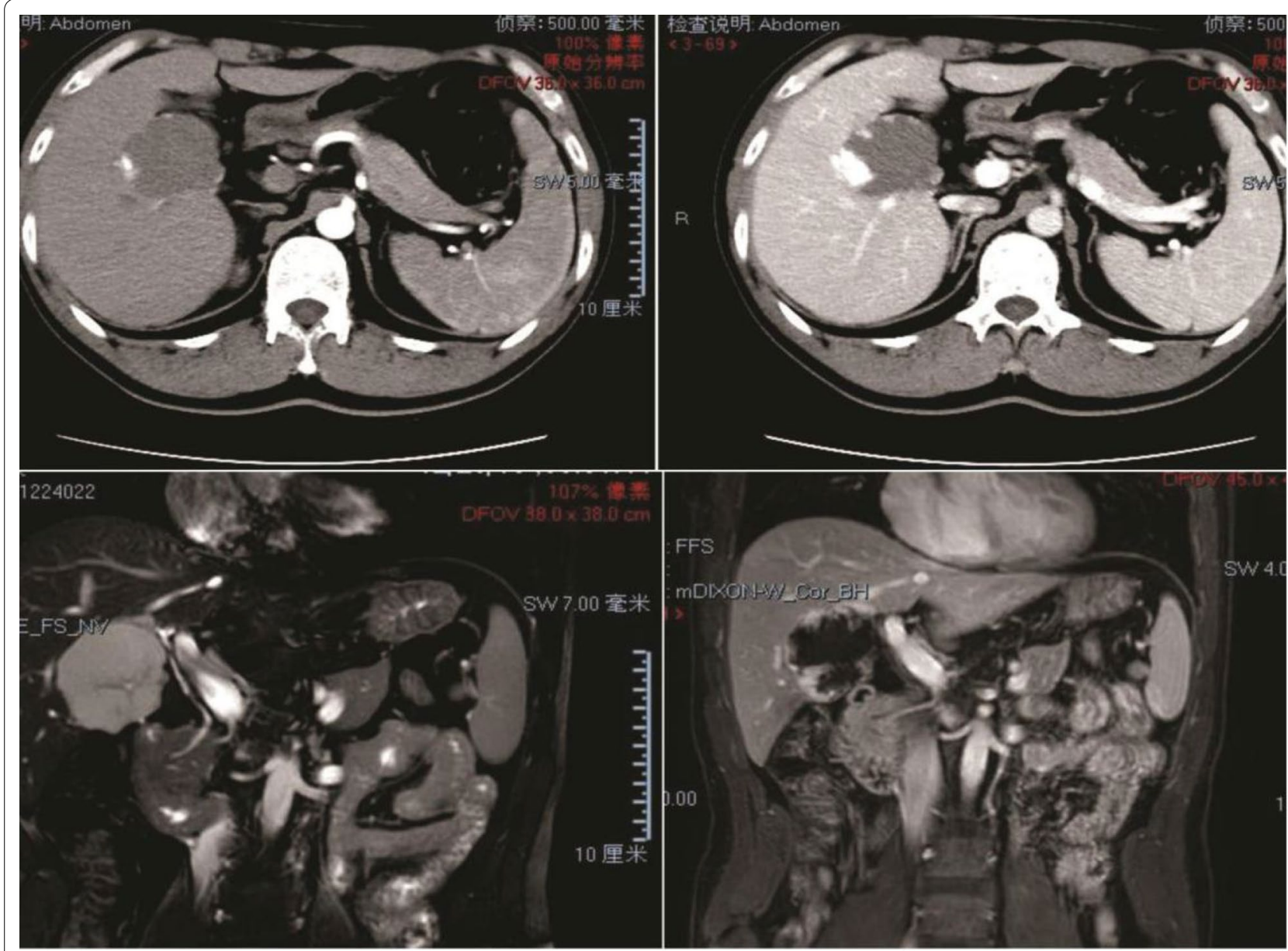

Fig. 3 A 45-year-old male patient, a seaman, had symptoms of obstructive jaundice and was diagnosed with a hepatic hemangioma about $5 \mathrm{~cm}$ in diameter near the first porta hepatis. CT and MRI images show the hepatic hemangioma at the first porta hepatis, compressing the intrahepatic bile duct, which caused obstructive jaundice. We enucleated the tumor and the patient's bilirubin level returned to normal

should be applied, and highly efficient electrosurgical instruments should be used to resect the liver. Intratumoral blood transfusion should be performed and a low central venous pressure should be maintained during the operation. Multiple small tumors should not be treated simultaneously, and TAE should not be used unless the tumor ruptures; radiofrequency or microwave treatment should not be used at all.

\section{Conclusion}

The present study showed that the indication for operation was giant $(>10 \mathrm{~cm})$ liver hemangioma, with or without symptoms, and that laparoscopic hepatectomy was an effective treatment option for hepatic hemangioma. For extremely giant hemangiomas, 3D image reconstruction was indispensable. Hepatectomy should be performed by experienced hepatic surgeons. 


\section{a}

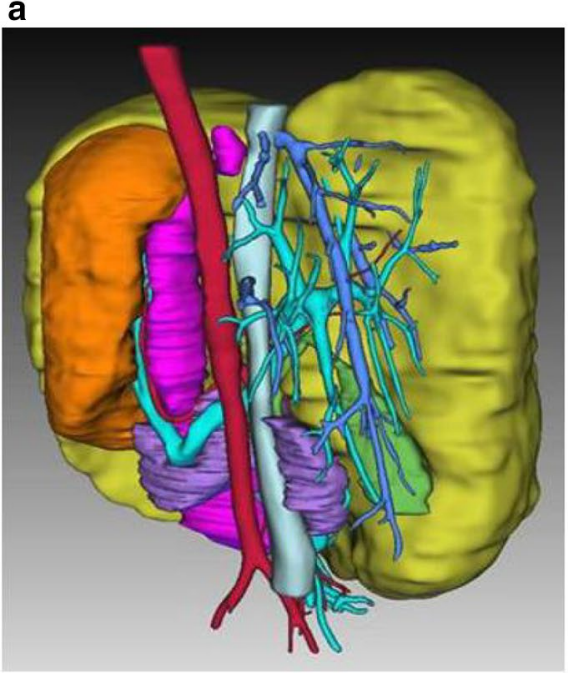

C

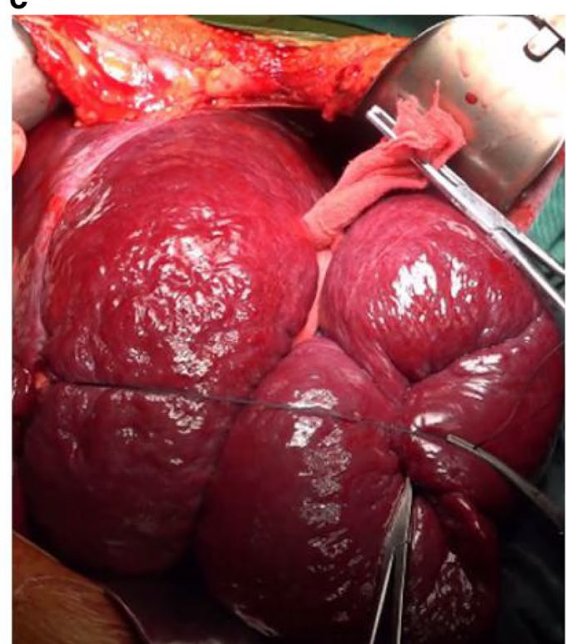

b

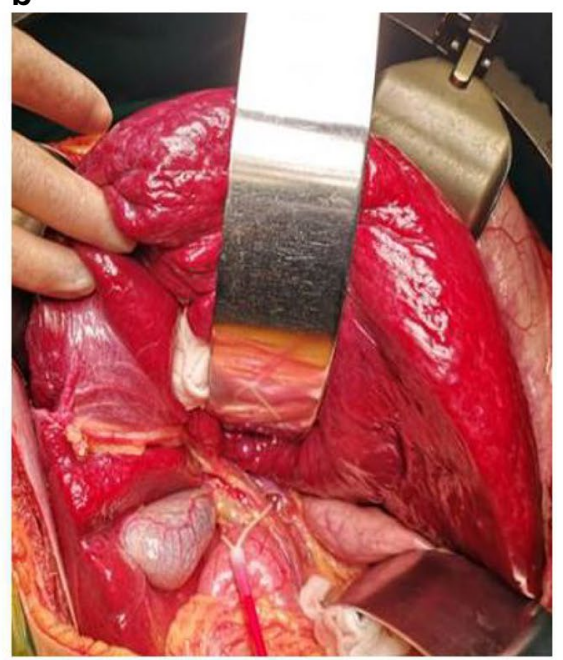

d

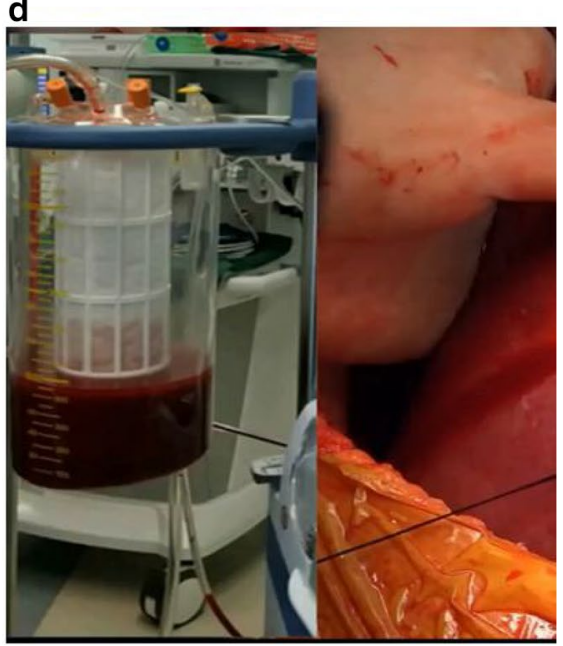

Fig. 4 Methods for the prevention of intraoperative bleeding. a 3D image reconstruction; b Prearrangement of a hepatic portal blocking band; c Bandaging of the tumor; $\mathbf{d}$ Autologous blood transfusion

\section{Abbreviations}

RFA: Radiofrequency ablation; RT: Radiation therapy; TAE: Trans-arterial embolization; 3D: Three-dimensional; CT: Computed tomography; MRI: Magnetic resonance imaging; LOS: Length of stay; HBV: Hepatitis b virus; AFP: Alpha fetoprotein; ICG: 15-Min indocyanine green clearance; TACE: Transhepatic arterial chemotherapy and embolization; CIK: Cytokine-induced killer cell.

\section{Acknowledgements}

This manuscript has been edited and proofread by Textcheck and the certificate can be acquired from the following link. http://www.textcheck.com/ login.

\section{Authors' contributions}

$\mathrm{XQ}$ designed this study; analyzed the data and drafted the paper. $\mathrm{XQ}, \mathrm{CZ}$ and $\mathrm{LF}$ collected the data and revised the manuscript. $\mathrm{XQ}, \mathrm{ZY}$ and $\mathrm{GH}$ supervised the data collection and inputting. GX and LF provided critical comments on various drafts of the paper. All authors read and approved the final manuscript.

\section{Funding}

There is no source of funding for research and/or publication.

\section{Availability of data and materials}

All data generated or analysed during this study are available from the corresponding author on reasonable request.

\section{Declarations}

\section{Ethics approval and consent to participate}

This study was approved by The Clinical Medical Research Ethics Committee of the First Affiliated Hospital of Anhui Medical University (Approval number: PJ2020-10-10 receipt date: 2020-08-12) and was performed in accordance with the Declaration of Helsinki. All patients or their authorizers gave written informed consent before the operation.

\section{Consent for publication}

The manuscript is approved for publication by all the authors. Written informed consent was obtained from the patients and/or their legal guardians for publication, and any accompanying images, sex, age of these patients.

\section{Competing interests}

The authors declare no competing interests. 
Received: 18 February 2021 Accepted: 25 March 2021

Published online: 08 April 2021

\section{References}

1. Choi BY, Nguyen MH. The diagnosis and management of benign hepatic tumors. J Clin Gastroenterol. 2005;39(5):401-12.

2. Adam YG, Huvos AG, Fortner JG. Giant hemangiomas of the liver. Ann Surg. 1970;172(2):239-45.

3. Lopez-Arce Angeles G, Barahona-Garrido J, Tellez-Avila Fl, et al. A giant hepatic hemangioma treated successfully with hepatic enucleation. Ann Hepatol. 2009;8(4):377-8.

4. Gandolfi L, Leo P, Solmi L, Vitelli E, Verros G, Colecchia A. Natural history of hepatic haemangiomas: clinical and ultrasound study. Gut. 1991;32:677-80.

5. Pietrabissa A, Giulianotti P, Campatelli A, et al. Management and followup of 78 giant haemangiomas of the liver. Br J Surg. 1996;83:915-8.

6. Tak WY, Park SY, Jeon SW, et al. Ultrasonography-guided percutaneous radiofrequency ablation for treatment of a huge symptomatic hepatic cavernous hemangioma. J Clin Gastroenterol. 2006;40:167-70.

7. Gao J, Ke S, Ding XM, Zhou YM, Qian XJ, Sun WB. Radiofrequency ablation for large hepatic hemangiomas: initial experience and lessons. Surgery. 2013;153:78-85.

8. Park SY, Tak WY, Jung MK, et al. Symptomatic-enlarging hepatic hemangiomas are effectively treated by percutaneous ultrasonography-guided radiofrequency ablation. J Hepatol. 2011;54:559-65.

9. Ng KK, Lam CM, Poon RT, Shek TW, Ho DW, Fan ST. Safety limit of largevolume hepatic radiofrequency ablation in a rat model. Arch Surg. 2006;141:252-8.

10. Belli L, De Carlis L, Beati C, Rondinara G, Sansalone V, Brambilla G. Surgical treatment of symptomatic giant hemangiomas of the liver. Surg Gynecol Obstet. 1992;174:474-8.

11. Gaspar L, Mascarenhas F, da Costa MS, Dias JS, Afonso JG, Silvestre ME. Radiation therapy in the unresectable cavernous hemangioma of the liver. Radiother Oncol. 1993;29:45-50.

12. Seo HI, Jo HJ, Sim MS, Kim S. Right trisegmentectomy with thoracoabdominal approach after transarterial embolization for giant hepatic hemangioma. World J Gastroenterol. 2009;15:3437-9.

13. Giavroglou C, Economou H, loannidis I. Arterial embolization of giant hepatic hemangiomas. Cardiovasc Intervent Radiol. 2003;26:92-6.

14. Srivastava DN, Gandhi D, Seith A, Pande GK, Sahni P. Transcatheter arterial embolization in the treatment of symptomatic cavernous hemangiomas of the liver: a prospective study. Abdom Imaging. 2001;26:510-4.

15. Vassiou K, Rountas H, Liakou P, Arvanitis D, Fezoulidis I, Tepetes K. Embolization of a giant hepatic hemangioma prior to urgent liver resection. Case report and review of the literature. Cardiovasc Intervent Radiol. 2007;30:800-2.

16. Zeng Q, Li Y, Chen Y, Ouyang Y, He X, Zhang H. Gigantic cavernous hemangioma of the liver treated by intra-arterial embolization with pingyangmycin-lipiodol emulsion: a multi-center study. Cardiovasc Intervent Radiol. 2004;27:481-5.

17. Yamamoto T, Kawarada Y, Yano T, Noguchi T, Mizumoto R. Spontaneous rupture of hemangioma of the liver: treatment with transcatheter hepatic arterial embolization. Am J Gastroenterol. 1991;86:1645-9.

18. Zhong L, Men TY, Yang GD, et al. Living donor liver transplantation for giant hepatic hemangioma using a right lobe graft without the middle hepatic vein. World J Surg Oncol. 2014;12:83.

19. Longeville $\mathrm{JH}$, de la Hall $\mathrm{P}$, Dolan $\mathrm{P}$, et al. Treatment of a giant haemangioma of the liver with Kasabach-Merritt syndrome by orthotopic liver transplant a case report. HPB Surg. 1997;10:159-62.

20. Vagefi PA, Klein I, Gelb B, et al. Emergent orthotopic liver transplantation for hemorrhage from a giant cavernous hepatic hemangioma: case report and review. J Gastrointest Surg. 2011;15:209-14.

21. Ferraz AA, Sette MJ, Maia M, et al. Liver transplant for the treatment of giant hepatic hemangioma. Liver Transpl. 2004;10:1436-7.

22. Kumashiro $Y$, Kasahara M, Nomoto K, et al. Living donor liver transplantation for giant hepatic hemangioma with Kasabach-Merritt syndrome with a posterior segment graft. Liver Transpl. 2002;8:721-4.
23. Nichols FC III, van Heerden JA, Weiland LH. Benign liver tumors. Surg Clin N Am. 1989;69:297-314.

24. Yoon SS, Charny CK, Fong Y, et al. Diagnosis, management, and outcomes of 115 patients with hepatic hemangioma. J Am Coll Surg. 2003;197:392-402.

25. Hamaloglu E, Altun H, Ozdemir A, Ozenc A. Giant liver hemangioma: therapy by enucleation or liver resection. World J Surg. 2005;29:890-3.

26. Lerner SM, Hiatt JR, Salamandra J, et al. Giant cavernous liver hemangiomas: effect of operative approach on outcome. Arch Surg. 2004;139:818-21.

27. Singh RK, Kapoor S, Sahni P, Chattopadhyay TK. Giant haemangioma of the liver: is enucleation better than resection? Ann R Coll Surg Engl. 2007:89:490-3.

28. Donati M, Stavrou GA, Donati A, Oldhafer KJ. The risk of spontaneous rupture of liver hemangiomas: a critical review of the literature. J Hepatobiliary Pancreat Sci. 2011;18:797-805.

29. Newhook TE, LaPar DJ, Lindberg JM, Bauer TW, Adams RB, Zaydfudim VM. Morbidity and mortality of hepatectomy for benign liver tumors. Am J Surg. 2016;211:102-8.

30. Özdemir E, Akbulut S, Kutlutürk K, Yılmaz S. Giant hepatic hemangioma: an unusual cause of gastric compression. Turk J Gastroenterol. 2019;30(10):930-1. https://doi.org/10.5152/tjg.2019.18778.

31. Akbulut S, Yilmaz M, Kahraman A, Yilmaz S. Bilateral lower limb edema caused by compression of the retrohepatic inferior vena cava by a giant hepatic hemangioma. Int Surg. 2013;98(3):229-33.

32. Aydin C, Akbulut S, Kutluturk K, Kahraman A, Kayaalp C, Yilmaz S. Giant hepatic hemangioma presenting as gastric outlet obstruction. Int Surg. 2013;98(1):19-23

33. Spitzer D, Krainz R, Graf AH, Menzel C, Staudach A. Pregnancy after ovarian stimulation and intrauterine insemination in a woman with cavernous macrohemangioma of the liver. A case report. J Reprod Med. 1997;42:809-12.

34. Reddy KR, Kligerman S, Levi J, et al. Benign and solid tumors of the liver: relationship to sex, age, size of tumors, and outcome. Am Surg. 2001;67:173-8.

35. Schnelldorfer T, Ware AL, Smoot R, Schleck CD, Harmsen WS, Nagorney DM. Management of giant hemangioma of the liver: resection versus observation. J Am Coll Surg. 2010;211:724-30.

36. Grieco MB, Miscall BG. Giant hemangiomas of the liver. Surg Gynecol Obstet. 1978;147:783-7.

37. van Tilborg AA, Nielsen $\mathrm{K}$, Scheffer $\mathrm{HJ}$, et al. Bipolar radiofrequency ablation for symptomatic giant $(>10 \mathrm{~cm}$ ) hepatic cavernous haemangiomas: initial clinical experience. Clin Radiol. 2013;68:e9-14.

38. Lim KJ, Kim KW, Jeong WK, et al. Colour Doppler sonography of hepatic haemangiomas with arterioportal shunts. Br J Radiol. 2012;85:142-6.

39. Doklestić K, Stefanović B, Karamarkovik A, et al. Spontaneous rupture of giant liver hemangioma: case report. Srp Arh Celok Lek. 2013;141:95-9.

40. Takamoto T, Hashimoto T, Ogata S, et al. Planning of anatomical liver segmentectomy and subsegmentectomy with 3-dimensional simulation software. Am J Surg. 2013;206:530-8.

41. Oshiro Y, Ohkohchi N. Three-dimensional liver surgery simulation: computer-assisted surgical planning with three-dimensional simulation software and three-dimensional printing. Tissue Eng Part A. 2017;23:474-80.

42. Tani K, Shindoh J, Akamatsu N, et al. Venous drainage map of the liver for complex hepatobiliary surgery and liver transplantation. HPB (Oxford). 2016;18:1031-8.

43. Schindl MJ, Redhead DN, Fearon KC, Garden OJ, Wigmore SJ. Edinburgh Liver Surgery and Transplantation Experimental Research Group (eLISTER): the value of residual liver volume as a predictor of hepatic dysfunction and infection after major liver resection. Gut. 2005;54:289-96.

44. Miura JT, Amini A, Schmocker R, et al. Surgical management of hepatic hemangiomas: a multi-institutional experience. HPB (Oxford). 2014;16:924-8.

45. Sakamoto Y, Kokudo N, Watadani T, Shibahara J, Yamamoto M, Yamaue $H$, Japanese Society of Hepato-Biliary-Pancreatic Surgery. Proposal of size-based surgical indication criteria for liver hemangioma based on a nationwide survey in Japan. J Hepatobiliary Pancreat Sci. 2017;24:417-25.

46. Alper A, Ariogul O, Emre A, Uras A, Okten A. Treatment of liver hemangiomas by enucleation. Arch Surg. 1988;123:660-1. 
47. Fu XH, Lai EC, Yao XP, et al. Enucleation of liver hemangiomas: is there a difference in surgical outcomes for centrally or peripherally located lesions? Am J Surg. 2009;198:184-7.

48. Morino M, Morra I, Rosso E, Miglietta C, Garrone C. Laparoscopic vs open hepatic resection: a comparative study. Surg Endosc. 2003;17:1914-8.

49. Buell JF, Cherqui D, Geller DA, et al. World Consensus conference on laparoscopic surgery: the international position on laparoscopic liver surgery: the Louisville statement, 2008. Ann Surg. 2009;250:825-30.

50. Dagher I, O'Rourke N, Geller DA, et al. Laparoscopic major hepatectomy: an evolution in standard of care. Ann Surg. 2009;250:856-60.

51. Li M, Zhang C, Zhang T, et al. Outcome using selective hemihepatic vascular occlusion and Pringle maneuver for hepatic resection of liver cavernous hemangioma. World J Surg Oncol. 2015;13:267.

52. Wang Y, Ji W, Zhang $X$, Tan J. Laparoscopic liver resection and enucleation of liver hemangioma with selective hepatic vascular occlusion: technique and indications. J Laparoendosc Adv Surg Tech A. 2017;27:944-50.

53. Veerankutty FH, Rather SA, Yeldho V, Zacharia BM, Tu SA, Venugopal B. Totally laparoscopic resection of an extremely giant hepatic hemangioma. Surg J (N Y). 2019;5(3):e110-2.
54. Yan Y, Cai X, Geller DA. Laparoscopic liver resection: a review of current status. J Laparoendosc Adv Surg Tech A. 2017;27:481-6.

55. Liu Q, Liu F, Ding J, Wei Y, Li B. Surgical outcomes and quality of life between laparoscopic and open approach for hepatic hemangioma: a propensity score matching analysis. Medicine (Baltimore). 2019;98:e14485.

56. Aslan A, Meye rZu Vilsendorf A, Kleine M, Bredt M, Bektas H. Adult Kasabach-Merritt syndrome due to hepatic giant hemangioma. Case Rep Gastroenterol. 2009:3:306-12.

57. Oak CY, Jun CH, Cho EA, et al. Hepatic hemangioma with Kasabach-Merritt syndrome in an adult patient. Korean J Gastroenterol. 2016;67:220-3.

\section{Publisher's Note}

Springer Nature remains neutral with regard to jurisdictional claims in published maps and institutional affiliations.
Ready to submit your research? Choose BMC and benefit from:

- fast, convenient online submission

- thorough peer review by experienced researchers in your field

- rapid publication on acceptance

- support for research data, including large and complex data types

- gold Open Access which fosters wider collaboration and increased citations

- maximum visibility for your research: over $100 \mathrm{M}$ website views per year

At BMC, research is always in progress.

Learn more biomedcentral.com/submissions 